\title{
Epilogue: Indigenous worlds and planetary futures
}

\section{Bronislaw Szerszynski}

bron@lancaster.ac.uk

to appear in Rosalyn Bold (ed., forthcoming),

Climate Change as the End of the World, London: Palgrave Macmillan.

What does it mean to talk of 'the end of the world'? 'World' is a polyvalent word, unique to the Germanic languages, that in the history of its evolving meaning holds together in creative tension the human and the planetary, the spatial and the temporal, and the idea of human life as an independent given and that of it as always existing in relation to supernatural realities. But what if we took the word 'world' to mean 'planet'? According to modern cosmology, the world as a planet is four and a half billion years old and will probably last about another five before it is burnt up by an aging, expanding sun. Such a sentence only seems to make sense in the context of a particular 'episteme', involving interconnected ideas such as space-time, atoms, energy, galaxies, stars and planets, themselves supported by a vast interconnected set of knowledge practices, instruments and devices. Here the richness of the idea of a 'world' seems to have been lost; we seem to be a particularly long way from the 'worlds' of Amerindian peoples; and, in a literal sense, we seem to be a long way from the end of the world.

But there are aspects of our emerging understanding of planets that, I would argue, have a curious affinity with Amerindian thought. Planets are dense, folded spaces of mutuality, that still retain the imprint of their emergence from the immanence of the molecular cloud out of which the planetary system of which they are a part took form. As they coalesce into materially closed assemblages circling in the void, they differentiate internally, into different compartments and entities - which parts then come into close association in ways that shape and define and in a way 'sense' each other (Margulis 1998; Clarke and Hansen 2009). In these dense, folded spaces, phenomena such as life (Dupré 2012) and energy (Barry 2015) and geochemical processes are highly relational and processual phenomena through which apparently separate entities are connected in webs of interrelationship and transformation. And multiple temporalities are generated within the extended body of the planet, so that multiple world-beginnings and world-endings are internal to the process of planetary self-organisation, rather than singular book-ends to a unitary planetary story.

Although the empirical sciences of the Earth have played a huge role in shaping such insights, it sometimes feels as if Western scientific metaphysics is not in fact the best framework for articulating them - as if a deeper understanding of planetarity is struggling to get out of the straightjacket of Western naturalism. Indigenous ontologies - and not least the Amerindian and related cosmologies 
that are foregrounded in this book - might seem a more hospitable context for the features of planetary being listed above. This is of course not a wholly novel claim, but the essays in this collection give new depth to that intuition. Such cosmologies foreground fluidity and transformation, as different entities shift between what might otherwise be seen as wholly separate categories; multiple times seem to operate at once, and originary immanence is just a blink away; beings exist in and are defined by meshworks of reciprocity and generosity; grasping the deepest truth can involve departing radically from everyday perception and knowledge; everything is alive, aware, a potential interlocutor. In ways that are resonant with contemporary theory, the chapters suggest, the Earth is not a dead mechanism, but sensitive (Latour 2017), ticklish (Stengers 2015), and maybe dangerous (Hamilton 2017). And such cosmologies are grounded in forms of social metabolism that resonate with them: that involve passing on the 'accursed share' of excess production in moments of gift and festival, rather than reinvesting it in endless, industrial growth (Bataille 1988), and that resist the accelerating linear flows caused by tapping into fossil fuel and mineral deposits and thereby unleashing the gargantuan chemical energy gradient that lie between different strata of the Earth.

In an important paper, the philosopher Jane Howarth (1995) insists that the human tendency to make meaningful connections between the 'natural environment' and our inner 'mood' (by which she means affect without a clear object) can richly repay philosophical attention. To make that connection is not simply to make a causal claim: that the weather affects mood. Neither is it simply an anthropomorphism, a pathetic fallacy, a category mistake, a projection of capacities such as sentience, agency or emotions onto nonhuman or even nonbiological entities which (according to Western thought) do not and cannot possess those capacities. What are we doing, Howarth asks, when we say things like ' $\mathrm{t}$ ] he angry sea rages, thunders, is turbulent, frenzied, destructive, forceful, dashes against the cliffs' (Howarth 1995: 115)? Her answer is that part of learning what particular moods are involves experiencing the atmospheres of the natural world that correspond with them. The implication of this line of thought is that perhaps humans do not start with a fully-formed internal emotional world, which they then might project outwards onto the blank canvas of nature; it may be more true to say that humans-to-be arrive in the midst of a more-than-human world that already possesses different emotional tones - and that humans-to-be have to learn to introject these in order to structure and articulate their own inner experience, and thus become fully human.

The indigenous voices here enrich this insight beautifully. The peoples that inhabit these pages feel themselves to be open to forces in the environment around them. Teresa Brennan argues that the modern idea of psychic self-closure is inextricably linked with capitalist modernity, with its proliferation of commodities and technological domination of nature. In an echo of Latour's (1993) argument that, as modernity tries to separate and purify nature and culture, hybrids actually 
proliferate, she suggests that the notion of psychic closure from wider energetic flows has helped to drive the breathtaking energetic profligacy of modern society, and the incessant conversion of the energies of life into dead commodities (Brennan 2000). By contrast, accounts such as that of Bold (this volume) of how the air in the Andes is experienced by its peoples as suffused with moods, with animate and living presences, suggests a very different ecopolitics of 'vibrant matter' (Bennett 2010).

What does the end of a world look like? A world can be seen as a system of signs, and a system of signs can be disrupted and deranged. Gregory Bateson argued that because ecological order is semiotic, ecological collapse starts with a disruption in the communicative order of an ecosystem, which only later becomes manifest in physical changes (Bateson 1972). We see that in the essays here - that the semiotic relations between different beings together are shifting, no longer always make sense, and often seem to be moving away from liveliness and animacy. Comanduli for example (this volume) reports that the Ashaninka of Peru and Brazil can no longer trust the signs in the world around them on which they depend for their livelihoods. But if worlds are semiotic it does not mean that they are merely a set of signs to be perceived. This book remind us that a world is also a set of relations, obligations and mutual dependencies; the indigenous voices in these essays warn what happens when these relationships are not maintained. For the Masewal discussed by Questa (this volume), mountains are living, active entities or collections of entities, sentient 'reservoirs of life' that can repopulate the world with new beings - but are being killed by mega projects. In a comparable way, the Q'eqchi' Maya people in Permanto's account (this volume) speak of the tzuultaq'as, lords of the hills that dwell in hills and mountains, with whom an 'existential reciprocity' must be maintained - but say that the deforestation of a hill indicates that the tzuultaq'a of that particular hill is disempowered, or even dead.

The Anthropocene threatens to be an epoch of planetary forgetting (Szerszynski forthcoming), a loss not just of genetic, ecological and climate memory but also of cultural memory, as meaningful local places and their multispecies forms of life are deterritorialised into globalised non-places, defined only by their location in flows of resources and commodities. The chapters of this book give us many depressing example of these 'ends of the world'. But more, these essays show us that indigenous cultures give us a different way of thinking about what forgetting is. Unlike ontologically lazy westerners, who believe that the world arrives already as a unified, composed whole (Latour 2017: 86), and that it will go on existing whatever they do or do not do (Law 2002), we see that Amerindian peoples know that the world has to be actively maintained in being, through gift exchanges amongst humans and nonhumans, and that the apocalypse is an ever-present danger. For such peoples, in forgetting thus lies not just an epistemological tragedy but an ontological tragedy; they recognise that for the planet to endure in its power to go on, and its power of natality (Arendt 
1958) - the power to produce new beginnings as well as new endings - its memory systems have to be actively maintained. This means not just maintaining traditional knowledge, but also the subsistence practices and traditional lifeways that make such knowledge intelligible (Moeller 2018). Yet seeing the peoples of Latin America merely as custodians of an invaluable heritage would be an error. Like the wider movement of activists and researchers seeking to preserve and record biodiversity, to protect cultural diversity and political freedoms, to deepen our knowledge about environmental change, and to prevent the erosion of regulatory powers, indigenous peoples are not just building a museum for the actual. They are protecting the virtual - defending important, hardwon planetary preconditions that enable the future to arrive. As Danowski and Viveiros de Castro (2016: 123) put it, 'Amerindian collectives, with their comparatively modest populations, their relatively simple technologies that are nonetheless open to high-intensity syncretic assemblages, are a "figuration of the future", not a remnant of the past'. Those of us, anthropologists, activists and others, who see in indigenous thought and practice a vital element in the task of making the Earth's future otherwise have to attend to the important issues that Arregui (this volume) raises about environmental diplomacy and cosmopolitical translation as a 'controlled form of betrayal'. In making different ways of knowing speak to each other, in convening the 'people of Gaia' (Latour 2017), the threat of treachery and apostasy can never wholly be kept at bay.

But the messy task must continue. Indeed, I have argued (Szerszynski 2017) that we in the industrialised West have no longer any choice but to take notice of the 'earth beings' and other spiritual agencies reported in these pages and elsewhere. To paraphrase William Gibson's famous phrase about the future, 'the apocalypse is already here - it's just not evenly distributed'. Or as Evan Calder Williams puts it in his Combined and Uneven Apocalypse (2010), '[t]he world is already apocalyptic. Just not all at the same time'. This is a recognition that the end of the world has already happened for some (Danowski and Viveiros de Castro 2016) - but also that the 'combined and uneven' nature of the Anthropocene Earth extends to the spiritual realm. Let me expand on this. Trotsky's (1932) concept of 'combined and uneven development' itself combined Lenin's recognition that different societies progress at different speeds with his own insight that this unevenness was itself produced and maintained by imperialist economic relations. Spatial variegation is an inherent rather than accidental feature of the capitalist world system (Jessop 2011); it is not the case that different economies on the same planet can independently follow the same path and all come to enjoy the same benefits of advanced capitalism. If we abandon the linearity implied in Trotsky's ideas of stages, and of development as fast and slow, and instead see the 'unevenness' as about the coming into correspondence of different ontologies, we might call the Anthropocene a 'combined and uneven geospiritual formation'. The combination here implies we can no longer keep these other naturecultures 
at a distance - their agencies, stirred and uprooted by the industrial mobilisation of matter across the planet, are starting to haunt the subconscious of modernity, requiring new kinds of response (Szerszynski 2017). In such a context, books like Climate Change as the End of the World should become required reading.

\section{$\underline{\text { References }}$}

Arendt, Hannah (1958) The Human Condition, Chicago: University of Chicago Press.

Barry, Andrew (2015) 'Thermodynamics, matter, politics,' Distinktion: Journal of Social Theory, 16(1), pp. 110-25.

Bataille, Georges (1988) The Accursed Share: An Essay on General Economy, Vol. 1-3, New York: Zone Books.

Bateson, Gregory (1972) Steps to an Ecology of Mind: Collected Essays in Anthropology, Psychiatry, Evolution, and Epistemology, Aylesbury: Intertext.

Bennett, Jane (2010) Vibrant Matter: A Political Ecology of Things, Durham: Duke University Press. Brennan, Teresa (2000) Exhausting Modernity: Grounds for a New Economy, London: Routledge.

Clarke, Bruce and Mark B. N. Hansen (eds) (2009) Emergence and Embodiment: New Essays on SecondOrder Systems Theory, Durham, NC: Duke University Press.

Danowski, Déborah and Eduardo Viveiros de Castro (2016) The Ends of the World, Oxford: Polity.

Dupré, John (2012) Processes of Life : Essays in the Philosophy of Biology, Oxford: Oxford University Press.

Hamilton, Clive (2017) Defiant Earth: the Fate of Humans in the Anthropocene, Cambridge: Polity.

Howarth, Jane (1995) 'Nature's moods,' British Journal of Aesthetics, 35(2), pp. 108-20.

Jessop, Bob (2011) 'Rethinking the diversity of capitalism: varieties of capitalism, variegated capitalism, and the world market,' in Capitalist Diversity and Diversity within Capitalism, ed. Geoffrey T. Wood and Christel Lane, London: Routledge, pp. 209-37.

Latour, Bruno (1993) We Have Never Been Modern, tr. Catherine Porter, Hemel Hempstead: Harvester Wheatsheaf.

Latour, Bruno (2017) Facing Gaia: Eight Lectures on the New Climatic Regime, Cambridge: Polity.

Law, John (2002) Aircraft Stories: Decentering the Object in Technoscience, Durham, NC: Duke University Press.

Margulis, Lynn (1998) The Symbiotic Planet: A New Look at Evolution, London: Weidenfeld \& Nicolson. Moeller, Nina Isabella (2018) 'Plants that speak and institutions that don't listen: notes on the protection of traditional knowledge,' in Food Sovereignty, Agroecology and Biocultural Diversity: Constructing and Contesting Knowledge, ed. Michel P. Pimbert, London: Routledge, pp. 202-33.

Stengers, Isabelle (2015) In Catastrophic Times: Resisting the Coming Barbarism, tr. A. Goffey, Ann Arbor, MI: Open Humanities Press.

Szerszynski, Bronislaw (2017) 'Gods of the Anthropocene: geo-spiritual formations in the Earth's new epoch,' Theory, Culture \& Society, 34(2-3), pp. 253-75.

Szerszynski, Bronislaw (2019) 'How the Earth remembers and forgets,' in Political Geology: Active Stratigraphies and the Making of Life, ed. Adam Bobbette and Amy Donovan, London: Palgrave Macmillan, pp. 219-36.

Trotsky, Leon (1932) The History of the Russian Revolution, tr. Max Eastman, London: Victor Gollancz. Williams, Evan Calder (2010) Combined and Uneven Apocalypse, Winchester: Zero Books. 